\title{
Entre fachadas, bastidores e estigmas: uma análise sociológica do futebol feminino a partir da teoria da ação social de Erving Goffman
}

CDD. 20.ed. 796.05

796.33

http://dx.doi.org/10.1590/1807-55092015000400559

\author{
Leila SALVINI*** \\ J uliano de SOUZA****** \\ Wanderley MARCHI J ÚNIOR****
}

\section{*Departamento de Educação Física, Uni- versidade Federal do Paraná. \\ **Asociación Latinoa- mericana de Estudios Socioculturales del Deporte - Brasil. \\ ***Departamento de Educação Física, Uni- versidade Estadual de Maringá.}

No presente artigo temos por objetivo problematizar sociologicamente a participação feminina no universo futebolístico brasileiro, de modo a avançarmos no entendimento de como se constroem e se reconstroem algumas representações e estigmas do corpo feminino no contexto dessa prática esportiva. Para levarmos a efeito esse objetivo, nos respaldamos em uma série de elementos empíricos e teóricos que foram trabalhados de forma dialógica e relacional no decorrer do estudo. Do ponto de vista empírico, nos valemos de um conjunto de dados e informações coletadas por meio de entrevistas, observações de campo e pesquisa com imagens. Já do ponto de vista teórico, fizemos uso da teoria da ação social de Erving Goffman, tomando de empréstimo conceitos e noções fundamentais para a análise aqui proposta. A partir dessa articulação empírico-teórica, concluímos que o processo de construção corporal no contexto do futebol feminino brasileiro ocorre nos bastidores, enquanto a reconstrução corporal acontece de modo representativo na região de fachada.

Palavras-chave: Representações; Estigmas; Sociologia do esporte; Brasil.

\section{Introdução}

A presença das mulheres no universo esportivo brasileiro têm se demonstrado, ao longo da história, um processo cerceado de controvérsias e dilemas. Um indício disso que estamos argumentando se deu já nas primeiras décadas do século XX, quando algumas modalidades esportivas eram indicadas às mulheres pelos benefícios à saúde, à maternidade ou por reforçarem atributos "feminis", enquanto outras eram proibidas por esbarrarem nas prerrogativas higienistas e eugenistas que então se instauravam no país ${ }^{1-9}$.

Nesse particular, atividades que pudessem causar algum suposto tipo de dano aos órgãos reprodutivos das mulheres eram desencorajadas ${ }^{5}$, ao passo que as práticas corporais que envolvessem movimentos suaves, graciosos e que visassem o bem estar físico da "futura mãe" eram incentivados ${ }^{2}$. Nesse contexto em que se prevalecia fortemente uma ideia de renovação populacional, o corpo feminino acabou assumindo, sobretudo, o papel de reproduzir e gerar filhos fortes e saudáveis que defenderiam a então nação emergente.

As práticas esportivas femininas refreadas ou encorajadas táo logo se tornaram um assunto de Estado. A influência do poder político sobre a esfera esportiva determinou, especialmente por meio do Decreto-Lei 3.199/4a - que então regulamentava e estabelecia as bases legais de organização do desporto no país -, que as mulheres estavam expressamente "desaconselhadas" de praticarem atividades que não fossem adequadas à sua natureza ${ }^{1}$.

Interessante notarmos que mesmo com a revogaçấo do Decreto-Lei 3.199/41 no ano de 1979, uma espécie de "contrato social implícito" 10 acerca da participação das mulheres no esporte ainda situava seus corpos como alvos de tensóes e polêmicas. Essa movimentação social, por sua vez, indica que nem sempre mudanças operadas no âmbito legislativo implicam, de fato, em mudanças no espaço social 
mais amplo, de modo que o "reposicionamento" legal da mulher frente aos esportes que "feriam sua essência" não significou a quebra imediata de tabus, mitos e preconceitos direcionados histórica e socialmente em relação a esse grupo.

É na esteira, portanto, dessa argumentação suscitada que procuramos, ao longo do presente artigo, problematizar sociologicamente a participação feminina no universo futebolístico brasileiro, de modo a avançarmos no entendimento de como se constroem e se reconstroem algumas representaçóes e estigmas do corpo feminino no contexto dessa prática esportiva pautada tendencialmente em preceitos de dominação masculina ${ }^{11}$.

Para levarmos a efeito o objetivo delimitado para esse artigo, nos respaldamos numa série de elementos empíricos e teóricos que foram trabalhados de forma dialógica e relacional ${ }^{12}$ ao longo do estudo que deu origem a essa exposiçáa ${ }^{13}$. Do ponto de vista

\section{Método}

A pesquisa que deu subsídio a produção do presente artigo se caracterizou basicamente como qualitativo-descritiva ${ }^{14}$, tendo em vista que realizamos quatro entrevistas semi-estruturadas ${ }^{15}$, de duração média de 50 minutos cada, com jogadoras de uma mesma equipe. As jogadoras selecionadas para concederem as entrevistas deveriam ter participado de jogos oficiais representando a Seleção Brasileira de Futebol Feminino em pelo menos uma partida entre os anos de 2005 até 2011 (ano em que encerramos as entrevistas). Ressaltamos que todas as entrevistas foram realizadas no espaço onde aconteciam os treinamentos, em horários previamente acordados e de modo individualizado. Além disso, devemos frisar que todas as jogadoras no momento da entrevista (dezembro de 2010 a maio de 2011) atuavam por um clube da cidade de Curitiba/PR.

Destacamos também que foram feitas 15 visitas aos treinos, tendo como foco a interação inicial com essas jogadoras antes da efetivação das entrevistas. As observações sistematizadas foram realizadas durante o período que antecedia os treinos e jogos e findavam quando as jogadoras se retiravam do local (de treino/jogo).

Todas as jogadoras, o diretor de futebol feminino, treinadores e o presidente do clube foram informados sobre o estudo. As participantes diretas (jogadoras observadas e entrevistadas) assinaram ao Termo de Consentimento Livre e Esclarecido que empírico, nos valemos de um conjunto de dados e informaçóes coletadas por meio de entrevistas, observaçóes de campo e pesquisa com imagens. Já do ponto de vista teórico, fizemos uso da teoria da ação social de Erving Goffman, tomando de empréstimo conceitos e noçóes operatórias como, por exemplo: comportamentos regionais, regiāo de fachada, bastidores, representação social e estigma.

Em termos de organizaçáo do texto e distribuiçáo dos argumentos, nos aprouve primeiramente expor alguns dos preceitos metodológicos que orientaram a realizaçáo do estudo que animou a produção desse artigo. Em seguida, discutimos a teoria da ação social de Erving Goffman, procurando, na medida do possível, demonstrar algumas entradas e possibilidades de aplicação de seu "corpus" teórico para analisar o objeto empírico em tela. Na sequência, propomos uma análise dos dados empíricos por meio da teoria elencada e nos encaminhamos para o fechamento do artigo.

posteriormente passou pela apreciação e aprovação do Comitê de Ética da Universidade Federal do Paraná.

Dentre uma série de questóes levantadas na entrevista, procuramos indagar nossas informantes sobre a percepção estética e corporal que visualizavam no espaço do futebol. Mais precisamente, a questáo direcionada a essas agentes se apresentou nos seguintes termos: "Você acha que no futebol tem lugar para preocupação com a estética (no sentido de parecer atraente) do corpo ou o corpo nesse contexto deve, sobretudo, atender às necessidades fisicas do jogo?"

Outro material empírico utilizado no processo de construção deste estudo foi um ensaio fotográfico datado de 2011 e feito com as jogadoras de um importante clube do futebol feminino brasileiro, a saber, o Santos Futebol Clube. O referido ensaio consistiu de fotos sensuais produzidas com o intuito de integrar um calendário ${ }^{\mathrm{b}}$ que se inseriu em um conjunto de estratégias publicitárias da comemoração do centenário do Santos Futebol Clube. Vale ressaltar que as imagens que selecionamos do aludido calendário para compor nosso estudo não são desconexas e desprovidas de correlação com os demais materiais empíricos. A bem da verdade, tais imagens somam e completam as informaçóes coletadas por meio das entrevistas e das observaçôes, além de potencialmente reforçarem nossos apontamentos e reflexôes. 
Feitas essas ressalvas de caráter metodológico, avançamos à apresentação do referencial teórico que guiou nossas reflexôes, qual seja, a teoria da ação social formulada pelo sociólogo canadense Erving Goffman. Em termos da eleição do referencial teórico que subsidiou a análise das informaçôes produzidas e coletadas durante a pesquisa

\section{Referencial teórico}

\section{A teoria da ação social de ErvingGoffman}

Dentre as obras do sociólogo canadense Erving Goffman que foram traduzidas para o português destacam-se "A representação do eu na vida cotidiana" (original de 1959), "Manicômios, Prisões e Conventos" (original de 1961) e "Estigma - notas sobre a manipulação da identidade deteriorada" (original de 1963).

Na obra "A representação do eu na vida cotidiana”, o objeto central de análise é a chamada interação face a face e, no bojo desse inventário, o autor utiliza de metáforas sobre a representação teatral para descrever tais interaçôes. A tese central da obra é que os indivíduos em situação de interação "representam" papéis de forma bastante similar à performance realizada pelos atores em uma peça teatral. O trabalho de descrição destas representaçóes lança mão de outros conceitos relacionados ao teatro, com os de "desempenho", "cenário", "expressão" e "plateia"16.

É nessa obra também que o autor em tela sistematiza a noção de comportamentos regionais e a subdivide em região de fachada e região de fundos ou bastidores. Embora o objeto da discussão não seja o conceito de estigma, ele acaba permeando toda a análise erguida em torno dos comportamentos de fachada ou de bastidores. Daí a importância de entender-se a definição de estigma para depois retomar-se à noção de comportamentos regionais.

De acordo com Goffman ${ }^{17}$ existem três tipos de estigmas. Em primeiro lugar, há as abominações do corpo (deformidades físicas). Em segundo lugar, as culpas de caráter individual, percebidas como vontade fraca, paixôes tirânicas ou não naturais, crenças falsas e rígidas, desonestidade, sendo essas inferidas a partir de relatos conhecidos como distúrbio mental, prisão, vício, alcoolismo, homossexualismo, desemprego, tentativas de suicídio e comportamento político radical. Finalmente, há os estigmas tribais de raça, nação e religião, que podem ser transmitidos de campo, é oportuno frisar que esse processo não se deu de modo arbitrário e, ao invés disso, houve inicialmente uma preocupação em reunir criteriosamente o material empírico para depois submetê-lo, considerando, claro, o teor e potencialidade desse material, à apreciação e análise tendo como ponto de apoio a teoria das representaçôes de Goffman.

através de linhagem e contaminar por igual todos os membros de uma família.

Por estigma e representaçóes estigmatizantes no contexto do futebol feminino brasileiro, entendemos, em conformidade com GofFMAN ${ }^{17}$, que os mesmos se constroem pela ausência de caracteres socialmente aceitos e entendidos como de feminilidade nessa prática (tais como: graciosidade, açôes delicadas, cuidados de beleza etc.). Esse estigma, por sua vez, promove em indivíduos desinformados, preconceitos de cunho sexista frente às mulheres que praticam esse esporte, de modo que as atletas jogadoras de futebol, somente pelo fato de praticarem essa modalidade passam a ser automaticamente caracterizadas como desacreditáveis do seu papel feminino.

Tendo em vista que toda representaçáo realiza-se em uma região, entendemos que o estigma ou a necessidade de ocultamento do mesmo, subsidia a representação ou a relativa ausência dela. É, portanto, nesse contexto de espaços e representaçóes que Goffman ${ }^{18}$ estabelece a noção de comportamentos regionais, ou seja, açōes que ocorrem na região de fachada ou na região de fundos.

Segundo este sociólogo, uma região se define exclusivamente como qualquer lugar que seja limitado de algum modo por barreiras à percepção, que variam segundo o próprio grau em que tais barreiras são delimitadas e de acordo com os serviços expressos pelos meios de comunicação que também impõem barreiras a tal percepção.

GofFMAN $^{18}$ utiliza o termo "regiáo de fachada" para se referir ao lugar onde a representaçấo é executada, onde a cena acontece. Geralmente uma representação implicará somente em um único foco de atenção visual por parte do ator e da platéia. No entanto, muitas das representaçóes abrangem como partes constituintes círculos ou entáo aglomerados separados da interação verbal (p.101).

Todo o dispêndio de esforços e de tempo em elaborar uma representação se justifica na expectativa que o indivíduo cria em si mesmo, de que o papel 
representado seja levado a sério, que os observadores de fato acreditem no que estáo vendo. GofFman ${ }^{18}$ salienta que o indivíduo implicitamente pede aos "espectadores" para acreditarem que o personagem que vêem, no momento em questão, possui os atributos que aparenta possuir, que o papel que representa terá as consequências implicitamente pretendidas por ele e que, de um modo geral, as coisas são o que parecem ser (p.25).

Dando sequência à análise da regiâo de fachada, GOFFMAN $^{18}$ alega que quando a atividade corporal/ estética de alguém se exterioriza na presença de outras pessoas, alguns aspectos da atividade são expressivamente acentuados e outros, que poderiam desacreditar a impressão incentivada, são suprimidos.

Nesse caso, estamos diante de uma representação "oficialmente manipulada" e que pode ser entendida como toda atividade de um indivíduo que se passa na presença contínua diante de um grupo particular de observadores e que tem sobre estes alguma influência. Trata-se, em outras palavras, daquilo que Gofrman ${ }^{18}$ denominou de comportamento de fachada, isto é, um equipamento expressivo padronizado, intencional ou inconsciente empregado pelo indivíduo durante sua representação (p.29).

Prosseguindo nessa análise, a "fachada pessoal"c, por conseguinte, acontece em um cenário, que na visão de GoffMAN ${ }^{18}$, compreende a mobília, a decoração, a disposição física e outros elementos do pano de fundo que vão constituir os suportes do palco para o devido desenrolar da açáa (p.29).

Mesmo que práticas diferentes possam abranger a mesma fachada, o autor observa que uma determinada fachada social tende a se tornar institucionalizada em termos das expectativas estereotipadas abstratas às quais dá lugar e tende a receber um sentido e uma estabilidade. A fachada torna-se então, "[...] uma representação coletiva e um fato, por direito próprio"18 (p.34).

GOFFMAN $^{18}$ também destaca que as fachadas tendem a ser selecionadas e não criadas. Para tanto, podemos esperar que surjam dificuldades quando os que realizam uma dada tarefa são obrigados a selecionar para si uma fachada adequada entre muitas diferentes. Em síntese, a região de fachada trata-se de um espaço onde ocorre a representação e onde o ator interage de forma verbal ou gestual com os pares, necessitando, dentre outras coisas, que sua representação seja acreditada (p.34).

Já com relação à regiáo de fundos ou bastidores, Goffman argumenta que no espaço/momento que a mesma constitui ocorre uma diminuição ou uma potencial ausência de representação por parte dos atores. Pensemos, por exemplo, no espaço dos vestiários num campo de futebol, nos ambientes fora do contexto da visibilidade - o campo - ou então nos bastidores de ensaios fotográficos das jogadoras etc.

É importante reiterarmos que quando a atividade de algum ator se protagoniza na região de fachada, isto é, na presença de outras pessoas, alguns aspectos corporais e gestuais são acentuados, enquanto outros, que poderiam desacreditar a impressão acentuada, são suprimidos. Por sua vez, a regiāo na qual a supressão ocorre, pode ser chamada de região dos fundos, ou seja, de bastidores ${ }^{18}$ (p.106).

GOFFMAN ${ }^{18}$ entende a região de fachada ou bastidores como o lugar relativo a uma dada representação e onde a impressão incentivada pela encenação é sabidamente contradita como coisa natural. $\mathrm{O}$ autor afirma que é nesse local que se fabrica laboriosamente a capacidade de uma representação expressar algo além de si mesma. Trata-se, portanto, de um lugar onde as ilusões e impressões são abertamente construídas, pois, o ator pode descontrair-se, abandonar a sua fachada, abster-se de representar e sair da personagem (p.106-7).

Ademais, GofFMAN ${ }^{18}$ salienta que muito comumente a regiáo de fundo de uma representação fica localizada numa extremidade onde ela está sendo apresentada, ficando separada por uma divisáo e passagens protegidas. Muitas vezes, ela pode ser protegida visualmente. Em outras circunstâncias, a proteção pode ser de cunho sonoro. E ainda podem ser combinadas, tal como podemos perceber, por exemplo, no caso dos vestiários esportivos usados no futebol que isolam acústica e visualmente essas representaçóes.

GOFFMAN $^{18}$ assegura que é justamente nesse tipo de ambiente onde o ator pode sentir-se mais protegido e confiante para despir-se de si mesmo. Nesse sentido, ao esperar que nenhum membro do público penetre de maneira abrupta e comprometedora nesse "camarim", o ator sente-se a vontade para trazer à tona e compartilhar com seus pares, sua identidade real, se despindo da identidade virtual que representa na região de fachada. Quanto ao acesso à região dos bastidores, GofFman ${ }^{18}$ explana que:

Como os segredos vitais de um espetáculo são visíveis nos bastidores, e como os atores se comportam libertando-se de seus personagens enquanto estão lá, é natural esperar que a passagem da regiāo da fachada para a dos fundos seja conservada fechada aos membros do público ou que toda a regiáo do fundo se mantenha escondida deles. Esta é uma técnica de manuseio da impressão largamente praticada e requer um exame mais detalhado (p.107). 
A linha que divide as regiôes de fachada e de fundo é exemplificada em vários contextos de interação social em nossa sociedade. Um desses exemplos pode ser vislumbrado em restaurantes, nos quais a cozinha é isolada do espaço onde ficam as mesas, ou mesmo quando uma falsa impressão de acesso é criada, a partir de divisórias de vidro entre os bastidores - cozinha - e a fachada - as mesas - que permitem ver determinadas açóes naquele local. Outro exemplo são os banheiros que se localizam geralmente nas extremidades da casa, não fazendo parte das áreas comuns como a sala.

Com relação à entrada de intrusos nessa região, GoffMAN $^{18}$ explica que, os atores dispóem-se a iniciar a representação que encenam numa região de fachada, e esta súbita prontidáo em agir de uma determinada forma traz, no mínimo, uma confusão

\section{Resultados e discussão}

\section{Representações e estigmas do futebol feminino brasileiro}

Como foi apontado, de um ponto de vista teórico, na seção anterior, o aparente conflito na escolha das fachadas pessoais ou de uma equipe pode ser observado também no espaço do futebol feminino ${ }^{\mathrm{d}}$, na medida em que as atletas devem incorporar, para um maior êxito social, a representação de feminilidade aplicada à sociedade no espaço de jogo, ou seja, quando estáo em ação dentro de campo. Esse feito, em inúmeros momentos, se reflete em uma representaçáo, muitas vezes, desacreditada por parte do público, já que a exigência de representar uma jogadora de futebol femininamente dócil, talvez não seja uma tarefa das mais fáceis e conjuga, portanto, diferentes expectativas.

Essas diferentes expectativas que se constroem tanto na representação esperada de feminilidade e também de atleta, se mesclam, pois como veremos no relato da informante 4, sua maior preocupaçáo na hora do jogo é com as condições físicas para executar as habilidades que a modalidade exige, mas sem deixar de lado alguns atributos que corroboram com a construção da representação de feminilidade "expectativada":

[...] meu cabelo está sempre muito bem arrumado para que não me atrapalhe, não uso maquiagem, claro um perfume, pra sair suada e não fedida. $\mathrm{O}$ importante é a concentração para entrar no jogo, você entra e tem uma partida pra ganhar. [...] é lógico uma arrumadinha no momentânea à linha de ação na qual os atores já estão empenhados. O autor reconhece que é quase certo haver embaraço nessas circunstâncias e compreende que o "intruso" seja tratado como se absolutamente não estivesse ali ou, sem qualquer cerimônia, que este mesmo "intruso" seja convidado a se retirar (p.131).

Feitos esses delineamentos teóricos, aqui tecidos e situados com vistas a demonstrar alguns dos aspectos estruturantes da teoria da ação social de Erving Goffman que se apresentam como de utilidade e valia para estudarmos as relaçóes sociais no contexto do futebol feminino como no futebol e no esporte de uma maneira mais ampla, damos continuidade ao artigo de modo a apresentar, por um lado, algumas das informaçôes coletadas no período em que estivemos inseridos no campo e analisar, por outro, esse "corpus" empírico com base nas ferramentas teóricas então mencionadas e expostas.

cabelo, brinco é impossível colocar, maquiagem você pode até colocar, mas vai suar, [...] uma depilação nas pernas, uma sobrancelha bem feita, isso faz bem pro ego. Não me preocupo com a minha imagem de estar bonita, eu tenho mais preocupação em jogar bem do que estar bonita.

Como é possível observar, a informante relata que se preocupa mais com o jogo e menos com a aparência para atrair o olhar de outrem. Contudo, mesmo sem salientar, ela descreve que se preocupa em possuir alguns atributos entendidos sócio e culturalmente como uma representaçáo de feminilidade, tal qual, o cabelo comprido, sobrancelha feita e pernas depiladas, características que aparecem como um "pano de fundo" para a representação no momento do jogo.

A existência da preocupação com a representação ou com o comportamento de fachada sob a apreciação de um grupo relativamente familiar de observadores, é evidenciado no discurso de nossa informante 2: "[...] você tá muito em evidência dentro do campo, então é torcida, são seus pais, são amigos, é como se fosse um espetáculo, a hora que você vai subir no palco (entrar no campo) tem que estar bem".

Os cuidados com a aparência física atrelada aos preceitos culturais e históricos de feminilidade aparecem nesse âmbito como uma forma de naturalizar a representação feminina também no espaço do futebol, dentro de campo. É o que alega a informante 4:

Eu acho que é importante (parecer bonita), até porque o futebol sempre foi visto como um 
esporte masculino, eu acho que assim, não é porque você está fazendo um esporte que você tem que deixar de ser feminina, e pro futebol feminino eu acho que todas deveriam ser femininas, porque é o esporte. [...] as pessoas que vem ver o jogo além de ver um esporte ta vendo as mulheres que também tem a sua beleza, eu acho isso importante.

Consideremos nesse momento, o fato de as jogadoras não usarem mais os cabelos curtos ou raspados, concatenando possivelmente ou desejando concatenar à sua imagem de jogadora um símbolo socialmente atrelado à figura feminina - os cabelos longos ou unhas pintadas - o que, por conseguinte, evidencia, conforme GOFFMAN $^{17}$, que os sinais corporificados já considerados, sejam eles de prestígio ou de estigma, fazem parte, de fato, da identidade social dos atores (p.53).

Nesse sentido, é que Goffman ${ }^{18}$ reconhece e defende que: "[...] uma representação é "socializada", moldada e modificada para se ajustar à compreensão e às expectativas da sociedade em que é apresentada" (p.40). Aplicando-se essa visão ao futebol feminino brasileiro com respaldo nos próprios relatos das atletas até aqui evocados, é possível então dizer que essa representação construída e moldada sob os preceitos das expectativas sociais, se pauta, sobretudo, na exposição de atributos de feminilidade fomentados em diferentes espaços sociais que não o esportivo espaço que, por muitos anos, foi território exclusivo do público masculino. Ao mesmo tempo, essas expectativas sociais também incidem no ocultamento de possíveis nuances de masculinização das jogadoras, visando, dessa maneira, diminuir ou evitar que se contemporize o estigma de que a mulher brasileira que joga futebol é isenta de atributos de feminilidade.

Diante, portanto, da necessidade de construção de uma representação coerente e necessária para uma melhor interação, GofFmaN ${ }^{17}$ adverte que alguns signos que transmitem informação social podem ser chamados de "símbolos". Em suas palavras:
Além dos símbolos de prestígio e dos símbolos de estigma, pode-se achar uma outra possibilidade, ou seja, um signo que tende - real ou ilusoriamente - a quebrar uma imagem, de outra forma coerente, mas nesse caso numa direção positiva desejada pelo ator, buscando não só estabelecer uma nova pretensão, mas lançar sérias dúvidas sobre a validade da identidade virtual (p.40).

Além disso, é sempre bom frisarmos que é esse "apoio de identidade" fornecida pelos signos que irá construir a imagem fotográfica do indivíduo na mente dos outros ${ }^{17,19}$. Desse modo, os símbolos se apresentam como uma técnica de controle da informação através da manipulação corporal, visando manter, sobretudo, a credibilidade da representação ${ }^{17-18}$.

Os registros fotográficos "extra-oficiais", feitos pelos meios de comunicação também nos remetem aos argumentos de Goffman, na medida em que tais registros visam e priorizam a exaltação de elementos que, por um lado, caracterizam a feminilidade e, por outro, produzem o ocultamento de preconceitos historicamente arraigados à figura da jogadora de futebol, como a homossexualidade, por exemplo ${ }^{13,20}$. O "pinçamento" dessas imagens por parte da mídia denota um trabalho de produção cultural onde se atrela a feminilidade ao futebol. A informante 1, corrobora, quando alega que “[...] eles (os responsáveis pela veiculação da informação) procuram quem tá com unha pintada e pedem pra colocar em cima da bola, pra tirar a foto". Nota-se, outrossim, um direcionamento da informação à dimensão da beleza em detrimento da ênfase nas habilidades esportivas.

Esse tipo de argumento se torna mais inteligível quando nos reportamos ao calendário da equipe feminina do Santos Futebol Clube produzido em abril de 2011 a partir de um desfile sensual seguido de um evento em menção comemorativa aos 99 anos do clube litorâneo e, principalmente, ao ano de comemoração de seu centenário que entáo se aproximara. Vale observarmos, nesse sentido, a imagem 1 e imagem 2 :
Fonte: Imagem 1 - Jornal Lancenet ${ }^{21}$; Imagem 2 - Folha de S.Paulo22.

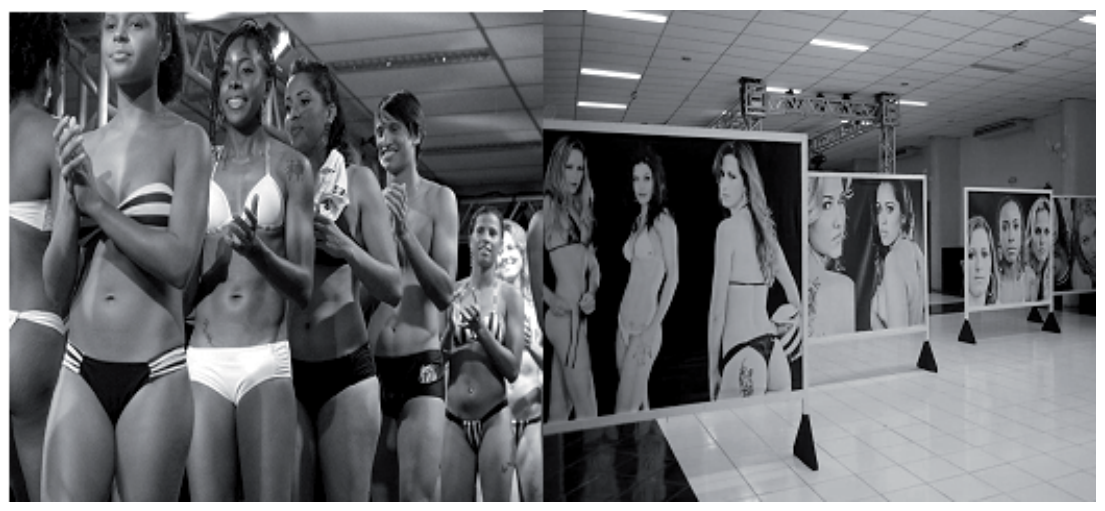

FIGURA 1 - Desfile de lançamento do calendário “As sereias da Vila”. 
Ambas as imagens, por um lado, nos remetem àqueles traços mais convencionais e normativos daquela identidade feminina tradicionalmente expectativada e fomentada em várias esferas constitutivas da sociedade. Esse processo é denominado por GofFMAN $^{19}$, como ritualização da feminilidade. O autor desenvolve e detalha essa ideia ao mencionar que: "[...] uma fotografia publicitária constitui uma ritualização de ideais sociais, de tal modo que tudo o que impeça o ideal desse manifestar é cortado, suprimido" ${ }^{19}$ (p.188). Essa ritualização de feminilidade normativa utilizada nas fotos publicitárias ilustradas nas imagens 1 e 2, também pode ser identificada durante uma interaçáo face-a-face com vistas à fazer valer uma representação entendida como "ideal".

Por outro lado, essas mesmas imagens nos permitem refletir sobre a utilização dos meios de comunicação para dar visibilidade aqueles atributos corporais da mulher-futebolista que, na maioria das vezes, não são percebidos no momento do jogo ou entáo são desacreditado ${ }^{20}$. Dito de outro modo, a veiculação social dessas imagens faz parte de um trabalho de agenciamento midiático no sentido de tornar crível o papel de feminilidade que está sendo buscado na representação da jogadora de futebol também num contexto de apresentação em campo ${ }^{6,13}$.

Para GofFman ${ }^{17,19}$, tanto os profissionais quando a indústria da comunicação tem conhecimento do efeito que a impressão momentânea produzida principalmente pela televisão - incluímos a internet - tem sobre a opiniáo de uma maciça audiência. Cientes dessa potencialidade, os produtores culturais- um dos grupos mais interessados, sem dúvida, em vender esse tipo de representação - tomam muito cuidado em construir a impressão correta, havendo, em contrapartida, grande ansiedade e receio quando se julga que a impressão produzida possa não ser conveniente.

KNIJNIK e VASCONCELLOS ${ }^{23}$ corroboram-nos nessa afirmaçāo ao se reportarem ao Campeonato Paulista de Futebol Feminino realizado em 2001, no qual, novas regras relacionadas à aparência das participantes foram implementadas. Dentre as novas regras, se incluía a proibição de atletas de cabelos raspados e a limitação de idade (as atletas não poderiam ter mais de 23 anos para jogarem). Os autores atribuem esses fatores à possibilidade das imagens de jogadoras mais feminilizadas e mais jovens apresentarem maior potencial de veiculação de cunho erotizável na mídia em geral.

Tais modificaçóes podem ser entendidas como artimanhas ou argumentos para atrair o público aos jogos femininos. Frente a essa análise, GoelLner ${ }^{4}$, sustenta que, agregado ao discurso de mercado que se pauta no custo e na falta de patrocínio como maiores empecilhos para o desenvolvimento desse esporte, ou ainda, da falta de condiçóes de manter-se nele, outro discurso que há muito tempo ronda os espaços onde acontece a prática de atividades físicas tais como o futebol, é o da masculinização das mulheres, discurso esse que, em última instância, prejudica a veiculação efetiva de uma representação de fachada, remetendo, muito possivelmente, essa trama construída em torno da imagem da mulher no futebol a uma representação de bastidor não muito lucrativa e vendável, mais ainda assim veiculada como estigma na grande mídia.

Já no tocante à regiáo de fundo do futebol feminino, é importante ressaltar que esse espaço corresponde ao lugar onde ocorre a preparação das atletas tanto para o jogo na sua conotaçáo tática quanto para sua entrada em campo - cena inicial em que as imagens das atletas estarão em voga e em constante prova. Além da modificação dos uniformes das equipes femininas que estấo mais ajustados, facilitando a locomoção e destacando o corpo das atletas ${ }^{13,24}$, sublinhamos a presença da preocupação de transitar e parecer com os cabelos bem arrumados, uniforme e chuteiras impecáveis e unhas feitas - artimanhas que visam relacionar a identidade da mulher jogadora de futebol à imagem da mulher presente em diferentes "locus" da sociedade, ocultando possíveis estigmas fomentados pela modalidade.

Nesse caso, podemos dizer que a manipulação corporal surge no universo do futebol feminino brasileiro com o intuito de reforçar a representação de feminilidade culturalmente construída no país ${ }^{25-27}$. Tal representação, por sua vez, passa a ser aceita e desejada tanto pelas atletas como pelos dirigentes. A esse respeito, as informantes destacam que não existem regras institucionalizadas que determinam o uso e a preocupação com "detalhes feminis", mas, deixam claro que existem incentivos para que isso, de fato, ocorra.

O incentivo por parte dos dirigentes e a aceitação e incorporação da representação de feminilidade por parte das jogadoras, segue a lógica de espetacularização dos corpos femininos no mercado ${ }^{13}$, de modo a contrabalançar estigmas homofóbicos presentes nessa prática esportiva ${ }^{20,28}$ e veicular uma "nova cara" do futebol feminino brasileiro nos meios de comunicação (materializado, dentre outras possibilidades, no calendário "As sereias da Vila", conforme vimos. Tal representação, por conseguinte, pode ser entendida no meio futebolístico como uma engrenagem cuja principal função é reorientar a imagem da mulherfutebolista no Brasil, de modo que, para esse desígnio, 
a mesma deve ser cúmplice e estar munida de atributos que ressaltem sua feminilidade dentro da então normatividade de gênero.

Levando em conta o histórico de exclusão das mulheres no futebol brasileiro, oficialmente legalizado nos anos 1940 com o Decreto que proibia a prática e atualmente ilustrado, dentre outras coisas, pela falta de incentivo, os fatos ocorridos nos bastidores - e muitas vezes na regiâo de fachada - geraram e ainda continuam gerando algumas polêmicas vinculadas à sexualidade das atletas. Não podemos negligenciar que no início da prática as jogadoras eram explicitamente questionadas quanto a sua sexualidade ${ }^{1,4,29-30}$, mas, com o passar do tempo e com o processo de investimento na regiáo de fachada visando o reforço de características feminis, tais insinuaçóes passaram a habitar a região de fundos.

Dessa forma, ao tratarmos de informaçóes da regiāo de fundos precisamos salientar que somente um agente legítimo ao contexto investigado é que vai conseguir coletar informações reais. Desse modo, uma jogadora de futebol poderá ter acesso às informaçóes dos bastidores que pesquisadores alheios ou pouco familiarizados a esse meio não teriam. Tendo em vista, portanto, o difícil acesso a essas informaçóes, o que pode ser feito são algumas incursóes preliminares relacionadas à identidade das atletas na regiáo de bastidores.

Como forma de esboçar um fato ocorrido na região de fundos e de elucidar a passagem em que GOFFMAN $^{18}$ trata de um início súbito de representação na regiāo de fundos quando um ator desconhecido adentra tal espaço, citamos o bloqueio de informaçóes - o qual, inclusive, tivemos a oportunidade de vivenciar durante o período de observação - aos não identificados como pares durante uma conversa, onde alguns termos (que pudessem explicitar a possível identidade real dos envolvidos) são substituídos por outros. A título de exemplo, devemos lembrar que a informante 2 ao conversar com as colegas de equipe se referiu a companheira da informante 1 como sendo sua prima e não, de fato, como sua companheira, de modo a proteger elementos de sua identidade diante de "intrusos", ou seja, dos pesquisadores.

À guisa de apontamentos finais é necessário destacarmos a partir da fala de nossas informantes (as jogadoras) que existe sim uma preparação cuidadosa investida na região dos bastidores (nos vestiários) para gerar uma boa e convincente representaçáo na região de fachada, que consiste em apresentar elementos relacionados à feminilidade, mesmo num espaço de jogo definido pelo combate.
Devemos também notar que o futebol no Brasil, de fato, carrega um simbolismo atrelado ao papel masculino de combate e, além disso, que mesmo após as mulheres adentrarem aos gramados e outros espaços da vida social ocupados em outros tempos unicamente pela figura do homem, ainda se faz necessária a presença de atributos - entendidos como - de feminilidade para que as jogadoras sejam ausentadas do estigma que assola suas sexualidades ${ }^{13,20}$.

Nesse contexto, destacamos que o esforço maior empreendido na região de fachada do futebol feminino brasileiro visa apresentar suas atletas ao grande público ou à mídia como portadoras de atributos socialmente categorizados como de feminilidade, entendendo que esse é o padrão do "ser feminina", independentemente da prática em que estão envolvidas, salientando, além disso, que um esporte coletivo com contato físico entre os oponentes, tal como o futebol, exige tendencialmente dos/das praticantes preparação física específica e adequada para um bom desempenho na modalidade.

Após esses apontamentos - e nos posicionando de forma reflexiva e crítica com relação aquele olhar unilateral fomentado pela visão heteronormativa em que o sexo e a sexualidade orientam a construção do corpo generificado - , compreendemos que a região de fachada do futebol, seja ela no campo ou no produto final das fotos, visa o reforço da apresentaçáo do gênero feminino estereotipado, principalmente se considerarmos o contexto histórico de preconceito de cunho sexista que se impóe sobre as praticantes de futebol no Brasil. Ainda no bojo dessa análise, ressaltamos o interesse midiático na veiculação de uma imagem heteronormativa e feminilizada que ajude a expandir a oferta e consumo da modalidade no país por meio da espetacularização de corpos revestidos de características "feminis", socialmente aceitas e, portanto, facilmente reproduzíveis.

Tendo em vista que o respaldo midiático é vantajoso tanto para as atletas quanto para os clubes, e, entendendo que a lógica da veiculação dessas informaçōes repousa - grosso-modo - sob o clichê "ser mulher, jogar futebol e ainda continuar sendo mulher", as equipes, de um modo geral, acabam se ajustando às exigências pautadas nas expectativas de "desmistificar" a ideia de que as jogadoras de futebol são desprovidas de características que as aproxime do normativo "papel feminino", ajustando o foco das reportagens para questóes de beleza em detrimento da discussáo sobre as habilidades esportivas das atletas ${ }^{31-32}$.

Nesse sentido, a necessidade de associar ao universo do futebol feminino, elementos e atributos de beleza física das jogadoras se dá de forma 
manipulada e por intermédio dos serviços oferecidos, sobretudo, pela indústria de comunicação ${ }^{17-19}$. Some-se a esse prognóstico, o fato primeiramente de o esporte exigir de seus praticantes habilidades físicas que vão tendencialmente "esculpir" corpos de acordo com a necessidade de cada modalidade em si e, em segundo lugar, que nem sempre tais corpos vão atender às expectativas convencionais de gênero, apresentando, dessa forma, um modo plural de ser mulher que nem sempre é acreditado - nos termos de Goffman - aos olhos normativos.

É correto dizer, portanto, que a representação na região de fachada manipula as informaçóes a respeito das jogadoras enquanto indivíduos e da modalidade como um todo. Dessa maneira, ao se apresentarem nessa região de acordo com os pressupostos normativos de gênero, as atletas buscam, muitas vezes, sem saberem disso ou terem plena consciência disso, camuflar ou anular informaçóes dúbias que possam ou venham a ser aventadas sobre suas identidades. Além disso, essa representação feminilizada dos corpos - no sentido de espetacularização - tem maior legitimidade ao mostrar essas mulheres-atletas na mídia, reafirmando, em contrapartida, a dicotomia de gênero em um esporte considerado por muitos como estritamente masculino ${ }^{33}$.

Por fim, convém recuperarmos o objetivo do texto, qual seja, analisar com base na teoria de Goffman como são construídas e se reconstruídas algumas representaçóes e estigmas do corpo feminino no contexto do futebol brasileiro, e avalizar, de modo preliminar, que o processo de construção corporal das jogadoras ocorre na regiáo de fundos ou nos bastidores, ao passo que a reconstrução corporal é criada, reforçada e manipulada na região de fachada sob os olhares e expectativas dos demais atores.

É sempre importante lembrar que nossa argumentação se respalda no fato de que os bastidores minimizam a expectativa de ação no que tange a normatividade de gênero, possibilitando o desenvolvimento de novas formas de apresentação da feminilidade ou, nos termos utilizados por estudiosas das relaçóes de gênero, uma pluralidade de formas de ser feminina ${ }^{34-35}$. Com a possibilidade de descolarem-se das prerrogativas normativas ou estáticas de gênero, as atletas constroem corpos que visam atender primariamente as necessidades do esporte.

Em contrapartida, ao apresentarem-se em cena ou na região de fachada, fazendo uso de uma representação que em parte, remete à exaltaçáo de atributos ou aspectos que tendencialmente atendem à noção sócio-histórico-cultural da normatividade de gênero, as jogadoras de futebol procuram reforçar e dar credibilidade ao papel que lhes é imputado representar naquele momento para atender aos olhares e expectativas tanto dos aparatos midiáticos quanto dos dirigentes, patrocinadores e familiares.

Como última observação, reitera-se que esse texto consistiu num breve exercício de reflexáo sobre o futebol feminino brasileiro ensaiado a partir da teoria da ação social de Erving Goffman, teoria essa, a nosso ver, muito pertinente à análise, embora pouco utilizada. Além disso, essa breve reflexão promove o que podemos chamar de "choque" de expectativas, pois, a expectativa culturalmente construída com base na diferenciação dos gêneros para o papel feminino é conflitante com a expectativa que se tem da mulher-atleta e o desenvolvimento das habilidades físicas para a modalidade escolhida.

Desse modo, as expectativas geradas na regiáo de fachada do futebol feminino se fundem, para que seja possível a representação da "mulher feminina do futebol feminino" que, sobretudo vise atender e "não frustrar" nenhuma das expectativas, sob pena de ter a representação desacreditada perante o público. Assim sendo, podemos concluir que a construção e veiculação de representações e estigmas no futebol feminino se sustentam em dois alicerces diferentes: enquanto a regiâo de fachada estrutura e possibilita vender uma imagem ou representação feminilizada do futebol feminino ao maior número possível de pessoas, a região dos bastidores com suas nuanças e "silêncios" permanece marginalizada, distante dos olhos dos espectadores.

\section{Notas}

a. $\mathrm{O}$ artigo 54, para efeitos de esclarecimento, sanciona que: “[...] às mulheres não se permitirá a prática de desportos incompatíveis com as condiçôes de sua natureza devendo, para este efeito, o Conselho Nacional de Desportos baixar as necessárias instruçôes às entidades desportivas do país". O inteiro teor do decreto se encontra disponível em: http:// www6.senado.gov.br/legislacao/ListaPublicacoes.action?id=152593. [citado 9 set. 2010]. Esse mesmo decreto foi revogado no ano de 1975 pela lei 6251/75. Disponível em: http://www3.dataprev.gov.br/SISLEX/paginas/42/1975/6251.htm. [citado 9 set. 2010]. 
b. A ideia do calendário com poses sensuais de jogadoras de futebol, não é exclusividade das "Sereias da Vila” - como são conhecidas as jogadoras do Santos Futebol Clube. Em fevereiro de 2011, atletas do futebol espanhol do Alqueries CF, recorreram à venda de calendários com poses ousadas como forma de angariar recursos para subsidiar as viagens da equipe pelo país. Informação disponível em http://uolesporte.blogosfera.uol.com.br/2011/02/11/sem-patrocinio-time-femininode-futebol-apela-para-calendario-sensual/. [citado 15 mai. 2011]. Para um maior esclarecimento sobre o calendário do Santos F.C. ver: http://www.santosfc.com.br/multimidia/galerias/album.asp?id=3703. [citado 21 abr. 2011 ] .

c. Entre as partes da fachada pessoal podemos incluir os distintivos da função ou da categoria, vestuário, sexo, idade e características raciais, altura e aparência, altitude, padróes de linguagem, expressóes faciais, gestos corporais e coisas semelhantes ${ }^{18}$ (p.31).

d. Outras representaçóes podem ser identificadas em tantas outras modalidades ou países, no entanto, nosso recorte abrange o futebol feminino no Brasil, fato que justifica o direcionamento do nosso foco de análise e discussão.

e. "Extra-oficiais" diz respeito a registros fotográficos efetuados fora do espaço dos gramados, em situaçóes diversas como, por exemplo, no desfile e evento comemorativo que deu origem ao calendário do Santos F.C. que mais a frente faremos uso.

A autora Leila Salvini é aluna de Doutorado de Educação Física da Universidade Federal do Paraná.

\begin{abstract}
Between facades, backstage and stigmas: a sociological about female soccer from the theory of social action by Erving Goffman

In this article we aim to problematize, sociologically, the female participation in the Brazilian footballing universe, in order to advance the understanding on how some representations and stigmas of the female body are constructed and reconstructed on the context of this sport. For taking this goal to effect, we got supported in several empirical and theoretical elements that were wrought dialogic and relational during this study. From an empirical point of view, we made use of a set of data and information collected through interviews, field observations and images research. In a theoretical point of view, we made use of the theory of social by Erving Goffman, lending concepts and fundamental notions for the analysis proposed here. In this context, we concluded that the process of body construction on female Brazilian soccer occurs on backstage, while the body reconstruction happens in a representative manner on the facade sphere.
\end{abstract}

KEY WORDS: Representations; Stigmas; Sport sociology; Brazil.

\title{
Referências
}

1. Castellani Filho L. Educação física no Brasil: a história que não se conta. Campinas: Papirus; 1988.

2. Goellner SV. Imperativos do ser mulher. Motriz. 1999;5:40-2.

3. Goellner SV. Mulher e esporte no Brasil: entre incentivos e interdições elas fazem história. Pensar Prat. 2005;8:85-100.

4. Goellner SV. Mulheres e futebol no Brasil: entre sombras e visibilidades. Rev Bras Educ Fís Esporte. 2005;19:143-51.

5. Mourão L. Representação social da mulher brasileira nas atividades físico-desportivas: da segregação à democratização. Movimento. 2000;13:5-18.

6. Mourão L, Morel M. As narrativas sobre o futebol feminino: o discurso da mídia impressa em campo. Rev Bras Ciênc Esporte. 2005;26:73-86.

7. Franzini F. Futebol é "coisa para macho"?: pequeno esboço para uma história das mulheres no país do futebol. Rev Bras Hist. 2005;25:315-28.

8. Devide FP. Gênero e mulheres no esporte: história das mulheres nos Jogos Olímpicos Modernos. Ijuí: Unijuí; 2005.

9. Devide FP. História das mulheres na natação feminina brasileira. São Paulo: Hucitec; 2009.

10. Mattos P. A mulher moderna numa sociedade desigual. In: Souza J, organizador. A invisibilidade da desigualdade brasileira. Belo Horizonte: Editora da UFMG; 2006. p.153-96. 
11. Salvini L, Souza J, Marchi Júnior W. A violência simbólica e a dominação masculina no campo esportivo: algumas notas e digressões teóricas. Rev Bras Educ Fís Esporte. 2012;26:401-10.

12. Bourdieu P. Introdução a sociologia reflexiva. In: Bourdieu, P. O poder simbólico. Lisboa: Difel; 1989. p.18-56.

13. Salvini L. Novo Mundo Futebol Clube e o "velho mundo" do futebol: consideraçôes sociológicas sobre o habitus esportivo de jogadoras de futebol [dissertação]. Curitiba (PR): Universidade Federal do Paraná; 2012.

14. Neves JL. Pesquisa qualitativa características, usos e possibilidades. Cad Pesq Adm. 1996;1:1-5.

15. Flick U. Métodos qualitativos na investigação científica. 2a ed. Lisboa: Monitor; 2005.

16. Baptista da Silva PV. Goffman, discípulo de Mead? Intermeio: Rev Prog Pós-grad Educ UFSM. 2007;13:82-99.

17. Goffman E. Estigma: notas sobre a manipulação da identidade deteriorada. Rio de Janeiro: Guanabara Koogan; 2004.

18. Goffman E. A representação do eu na vida cotidiana. Petrópolis: Vozes; 1985.

19. Goffman E. A ritualização da feminilidade. In: Goffman, E. Os momentos e os seus homens. Lisboa: Relógio D’Água; 1999. p.154-89.

20. Ferretti MAC, Zuzzi RP, Viana AES, Vilha Junior FM. O futebol feminino nos Jogos Olímpicos de Pequim. Motriz. 2011;17:117-27.

21. Lancenet [homepage]. Rio de Janeiro: Grupo Lance. [citado 21 jun. 2011]. Disponível em: http://www.lancenet.com. $\mathrm{br} /$ galerias/sereias-brilham-no-lancamento-do-calendario-do-centenario-do-santos/.

22. Lançamento do calendário do Santos. Folha de S.Paulo. 14 abr. 2011: Esporte. [citado 21 jun. 2011]. Disponível em: http://fotografia.folha.uol.com.br/galerias/2648-lancamento-do-calendario-do-santos-fc\#foto-52140.

23. Knijnik JD, Vasconcellos EG. Sem impedimento: o coração aberto das mulheres que calçam chuteiras no Brasil. In: Cozac JR, organizador. Com a cabeça na ponta da chuteira: ensaios sobre a psicologia do esporte. São Paulo: Annablume; 2003. p.73-90.

24. Dornelles PG. O futebol feminino de várzea: uma análise cultural [monografia]. Porto Alegre (RS): Universidade Federal do Rio Grande do Sul; 2004.

25. Votre S, organizador. A representação social da mulher na educação física e no esporte. Rio de Janeiro: UGF; 1996.

26. Altmann H. Rompendo fronteiras de gênero: Marias (e) homens na educação física [dissertação]. Belo Horizonte (MG): Universidade Federal de Minas Gerais; 1998.

27. Silveira R. Esporte, homossexualidade e amizade: estudo etnográfico sobre o associativismo no futsal feminino [dissertação]. Porto Alegre (RS): Universidade Federal do Rio Grande do Sul; 2008.

28. Prado VM, Ribeiro AIM. Gêneros, sexualidades e Educação Física escolar: um início de conversa. Motriz. 2010;16:402-13.

29. Salvini L, Marchi Júnior W. Notoriedade mundial e visibilidade local: o futebol feminino na revista Placar na década de 1990. Soc Plu. 2013;1:144-59.

30. Salvini L, Marchi Júnior W. Uma história do futebol feminino nas páginas da revista Placar entre os anos de 19801990. Movimento. 2013;19:95-115.

31. Souza JSS, Knijnik JD. A mulher invisível: gênero e esporte em um dos maiores jornais diários do Brasil. Rev Bras Educ Fís Esporte. 2007;21:35-48.

32. Knjnik JD. A mulher brasileira e o esporte: seu corpo, sua história. São Paulo: Mackenzie; 2003.

33. Kolnes LJ. Heterosexuality as an organizing principie in women's sport. Int J Sociol Sport. 1995;30:61-77.

34. Jaeggaer AA. Mulheres atletas e a potencialização muscular e a construção de arquiteturas corporais no fisiculturismo [tese]. Porto Alegre (RS): Universidade Federal do Rio Grande do Sul; 2009.

35. Goellner SV. Gênero e esporte na historiografia brasileira: balanços e potencialidades. Rev Tempo. 2013;17:45-52.

ENDEREÇO

Leila Salvini

Centro de Pesquisa em Esporte, Lazer e Sociedade Departamento de Educação Física Setor de Ciências Biológicas Universidade Federal do Paraná R. Coração de Maria, 92 80210-132 -Curitiba - PR - BRASIL e-mail: leila.salvini@hotmail.com
Recebido para publicação: 10/10/2012

1a. Revisão: 25/11/2013

2a. Revisão: 11/ 03/ 2014

Aceito: 08/06/2014 